milk, cod-liver oil, phosphate of lime, and an infusion of hops given as a cold beverage at meals. The children remain as much as possible out of doors, and, as they are accustomed to the open air, they bear very well to have the windows wide open all day in winter.

Since the opening of this hospitable institution we have ordered sea-baths to all the children, but we discortinued them at the end of November, not beginning again before the month of March. Gradually we have shortened this interval, experience having taught us that, not only is there no disadvantage, but rather a very good effect, in continuing these baths in the open sea all through the winter. Thus, the baths were kept up last season to December 27 th and began again $\mathrm{cn}$ January 11 th ; even this short interruption would not have been necessary.

The temperature of the water does not fall below $12^{\circ} \mathrm{C}$, or $54^{\circ} \mathrm{F}$. As the children arrive in October, they get gradually accustomed to the cold saline hydrotherapic treatment. It is hardly necessary to add, that the baths are only of short duration, namely, from five to ten minutes, according to the temperature, and that they are not taken on rainy or exceptionally cold days, nor on Sundays, which leaves an average of twenty sea-baths a month. We are convinced that these short cold baths taken in winter have a particular tonic effect, and are preferable-at all events, in the Mediterranean-to baths of longer duration in summer, when the sea-water is nearly tepid.

Our children bear this treatment remarkably well; they get strengthened in a short time, and never have contracted any affection of the respiratory organs. As yet we have not had a single case of pneumonia or pleurisy, nor even of simple bronchitis. One child, even, who had not complained of any ailment, took its bath in the same way as the others, and had that same evening a confluent attack of measles. This disease took its normal course, and the cough was much less strong than is usually observed in similar cases.

We make the children affected by scoliosis or Pott's disease wear a Dr. Sayre's corset, which is taken off during the time they bathe. We do not receive coxalgic children at the stage of painful muscular contracture; we are of opinion that at this period only immobility and extension are indispensable; the baths would then be too exciting; but at every other stage of coxalgy we experienced the most salutary effect from the saline hydrotherapic treatment. Even very abundant suppuration is by no means an indication against this treatment, but just the reverse. We do not only order sea-baths, but in many cases we apply bandages of cold sea-water, without neglecting those of boracic, salicylic, carbolic acid, or iodoform. Most children, and especially those suffering from scoliosis, are made to perform gymnastic exercises, and some are subjected to the cure of massage.

The results obtained last season were the following :-

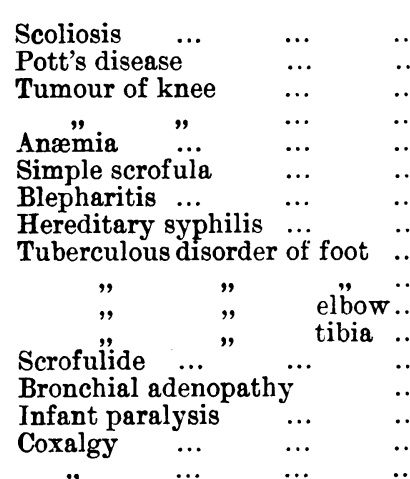

$\begin{array}{cl}\text { Cases. } \\ 1 & \text { Great improvement. } \\ 3 & \text { "̈ } \\ 2 & \text { Perfect cure. } \\ 2 & \text { In progress of recovery } \\ 7 & \text { Perfect cure. } \\ 1 & \text { Sudden death. } \\ 1 & \text { Improvement. } \\ 1 & \\ 3 & \text { Perfect cure. } \\ 2 & \text { In progress of recovery } \\ 1 & \text { Perfect cure. } \\ 1 & \text { " \#" } \\ 1 & \text { Improvement. } \\ 1 & \text { Perfect cure. } \\ 1 & \text { Great improvement. } \\ 5 & \text { Perfect cure. } \\ 2 & \text { Great improvement. }\end{array}$

Thus, all children have either been cured or are on the way to recovery, excepting one, which died suddenly during the night, probably from a clot in the heart. One of our coxalgic patients had a deep abscess in the hip-joint region; the baths were stopped for a few days during the formation of the pus, which was opened and drained. Three days after the operation the child resumed the usual routine of sea-baths. The boy suffering from tuberculosis of the elbow had his arm in such a deplorable state of tumefaction, profuse suppuration, disorder in the bone, etc., that the question had arisen of an extensive resection or even of an amputation. Notwithstanding this, an absolute cure was obtained without any further operation than the extirpation of a few pieces of bone.

These experiences justify the conclusion that the proper treatment of scrofula consists in keeping the children, climate permitting, in the open air, in sunshine, and in prescribing sea-baths to them, especially in winter.

\section{REMARKS ON A CASE OF GASTROSTOMY.}

\section{Read in the Section of Surgery at the Annual Meeting of the}

British Medical Association, held in Glasgow, August, 1888.

By ARCHIBALD CARMICHAEL, M.A., M.D.ABERD., Honorary Surgeon, North Lonsdale Hospital.

M. A. consulted me on January 3rd, 1888. She said she was 38 years of age, married, and had four children. The youngest, aged 14 months, she was then nursing at the breast.

There was no history of cancer or other hereditary disease in her family, except that her father died of phthisis, said to have been caused by his occupation of a stonemason.

She said she enjoyed good health up to three months before consulting me. She then began to lose flesh and strength, and to have difficulty in swallowing; and these symptoms were becoming more and more marked. She presented the appearance of a woman suffering from over-nursing. She pointed to the thyroid gland and said it was there she felt the difficulty of swallowing. She said she had no pain there, but only a feeling of fulness. The thyroid was considerably enlarged, and she said it had increased in size lately, but there was no undue hardness or tenderness about it.

Nursing was stopped without much difficulty, and she took fluid food well, such as eggs beaten up in milk, beef-tea, etc. Her general health soon improved, but the difficulty in swallowing increased, and on January 19th I for the first time explored the gullet. I found an obstruction at the level of the lower edge of the thyroid gland, which allowed the passage only of a No. 11 gum-elastic catheter. No blood was seen on the instruments used, nor was any sign of blood afterwards seen in the evacuations.

On every third or fourth day from January 19th to February 25th I passed a No. 11 catheter. The instrument was more tightly grasped on being withdrawn than during insertion. On two occasions only was a little blood seen, though I found it impossible to pass a larger instrument. She said she swallowed more easily after the instrument had been passed, and she urged me to use it more frequently.

On February '25th I failed to pass the usual size, and next day with considerable difficulty I passed only No. 6, and there was some. bleeding. Up to this time she could swallow sufficient fluid food.

On March 6th rectal alimentation was commenced.

On March 18th there was more swelling in the region of the thyroid, and some tenderness, but there was no rise of temperature, which was usually subnormal. I, however, made exploratory punctures, but blood only came away.

The condition of the patient was now such that it was very evident that unless she were fed by the stomach she must very soon die, and on March 22nd I performed gastrostomy in the Barrow Hospital with the assistance of the surgical staff. The patient was extremely emaciated, and her body exhaled a marked cadaverous oỏour. The operation was that described by Dr. Greig Smith in his work on Abdominal Surgery; the incision parallel to the edge of the ribs. Carbolic spray was used, and other antiseptic precautions taken. The anæsthetic was chloroform, of which a very small quantity was found sufficient, and no vomiting took place either during or after the operation.

On the following day, twenty-three hours afterwards, I completed the operation by opening the stomach. I found the parts firmly glued together with lymph. She was then fed with ten ounces of milk, and afterwards every four hours with beef-tea and milk alternately. She was able to swallow a little tea and milk. The improvement in her appearance two days after the operation was very marked. She slept well, and said she felt well.

On the fifth, sixth, and seventh days there was great difficulty in preventing the half digested matters from escaping by the fistula. The gastric juice had dissolved the lymph that bound the parts together, and as the stitches were becoming loose all seemed very insecure. The patient, from loss of food and of rest, was becoming very weak. Several methods to prevent leakage were tried and found wanting, till I devised and used an inflating: 
tampon. It is hour-glass shaped, each half being inflated separately. When in use one-half is in the stomach, the other half outside. This was perfectly efficient in closing the fistula, and was quite comfortable to the patient.

Dr. Caddy, house-surgeon, afterwards fitted the feeding tube with the inflating tampon, and thus the nurses were able with ease to feed the patient without any loss of food.

After three weeks the parts were firmly united, and the fistula had assumed a valvular form, so that slight pressure with a small compress was found sufficient to retain the contents of the stomach.

Throughout, the temperature never rose above $100^{\circ} \mathrm{F}$., except on the ninth day after the operation, when pus formed in the neck and was discharged from one of the exploratory punctures I made on March 18th. Pus continued afterwards more or less to be discharged from this part.

On April 18th she left the hospital.

On June 9th she went to Morecambe to visit some friends, and she remained there till June 30th, when she returned to Barrow feeling very ill. Pneumonia developed, and she died on July 2nd, 102 days after gastrostomy had been performed.

I made a post-mortem examination of the body twenty-four hours after death. I found a cancerous mass in the gullet below the level of the thyroid, and the sinus in the neck was connected with it.

The stomach was adherent to the anterior abdominal wall and to the under surface of the liver. The fistula was near the centre of the anterior or upper surface of the stomach.

The absence of pain, and the almost entire absence of bleeding when instruments were passed, on the one hand, and on the other the narrowness of the stricture and its recent and rapid development, made the nature of the obstruction difficult to determine.

\section{CASE OF DOUBLE PYOSALPINX CURED BY ASPIRATION.}

Read in the Section of Surgery at the Annual Meeting of the British Medical Association, held in Glasgow, August, 1888.

BY R. H. BOURCHIER NICHOLSON, M.R.C.S.ENG., Surgeon to the Hull Royal Infirmary.

A. P., aged 23, servant, unmarried, was admitted to the Hull Royal Infirmary on April 25th, 1888, under my colleague Dr. E. Daly. She had pain in the left inguinal region three years ago. During the present attack she had had pain for a month in the same situation. Menstruation was regular, but the pain was much worse at that time, and there was much headache. There was no leucorrhœa. The urine was normal. The temperature was $101^{\circ}$ in the evening, and on the third day rose to $103^{\circ}$. She was treated for acute ovaritis with dysmenorrhœe by leeching, pot. brom., etc., for four weeks. I was then asked to see her. I found the abdomen so tender in both iliac regions that she could not bear the slightest pressure. We had her put under ether, and made a careful examination in consultation with my colleagues. We found that there was a swelling in each broad ligament, on the right side the size of my fist, and on the left as large as a tangerine urange. By the bimanual method these could be distinctly made out; and as there had evidently been considerable inflammation in the region, shown by the fixed position of the uterus, I decided in the first instance to try aspiration through the vagina. Up to this time the evening temperature had ranged from $101^{\circ}$ to $103^{\circ}$, the girl losing flesh and evidently going rapidly wrong.

On May 17th I aspirated the right pyosalpinx, and evacuated four ounces of pus, after which I passed the aspirator into the left swelling, but nothing escaped except a little blood. Next morning the temperature was normal, where it remained for two days. It then gradually crept up to $101^{\circ}$ for five nights, when I again examined, and found the left swelling much enlarged; therefore I again aspirated it, when I removed three ounces of pus. Her temperature went down to normal, and only once again rose above $101^{\circ}$; this was on the second day after the second aspiration, when for some unexplained reason the temperature went up to $104^{\circ}$. She then made a steady convalescence, and was discharged on July 19th, cured.

Now this is a case in which I was advised to open the abdomen and remove the growths, etc., which would have been a decidedly more brilliant operation; but 1 think, as the result hus proved, the less heroic treatment was the better, and certainly the less dangerous.

\section{TALIPES EQUINO-VARUS IN THE ADULT: TWO SUCCESSFUL CASES OF DOUBLE OPERATION BY EXCISION OF A POR- TION OF THE TARSUS : DAVIES- COLLEY'S OPERATION.}

By F. R. FAIRBANK, M.D., F.S.A., Surgeon to the General Infirmary, Doncaster.

DuRING the year 1887 two extreme cases of talipes equino-varus in the adult were operated upon by me, according to Mr. DaviesColley's method, successfully. I beg to offer brief notes of them as a contribution to the discussion on "The Operative Treatment of Club-foot." Both my patients were over 40 years of age. In neither of them was the deformity congenital.

The first, J. D., reported that he was all right until about 13 years of age, when he was maltreated by his father and left, he believes, for dead. His feet became gradually so much distorted that when I saw him first he could place only the outer side of the little toe of each foot on the ground, and he could only move about on crutches. He begged of me to amputate both feet, as he thought he would be better off with stumps. I admitted him to the Doncaster Infirmary, and on February 15th, 1887, I operated on the left foot. I first divided the tendo Achillis and the tendon of the tibialis posticus, and then proceeded as directed in Erichsen's Surgery (eighth edition), making an incision on the outer side of the foot only. The foot was put up in plaster-of-Paris on March 26th, a window being left to dress the wound. By April 27 th the wound was entirely healed, and he could easily walk about with a little assistance. On May $3 \mathrm{rd}$ he was discharged to go to Southport Convalescent Home.

He was readmitted on June 7 th, 1887, for operation on the right foot, which was performed on June 9 th. I followed the same-line of operation, except that I made a free incision on the inside of the foot as well as on the outside. I found this rendered the operation easier, and gave freer vent to the subsequent discharge. The wounds were kept aseptic, the temperature rising once-the day after operation-to $100^{\circ} \mathrm{F}$., but not again. On July 12th plaster-of-Paris was applied, and he was discharged soon after to again go to Southport Convalescent Home. On January 24th, 1886 , the feet were 'both straight; and he could walk alone well; up and dowil stairs and out of doors. There was, however, a projection on the outer side of the right foot over the tarsus, which caused him pain when he had been walking some distance. I therefore removed a further slice of bone. Recovery was rapid, the wound being kept aseptic. His feet are of the natural form, but shorter than is usual. He can now walk well.

My second case, John F., a heavy, broad-built man, aged 41 , was admitted to the intirmary and operated upon on April 15th, 1887. He reported that he was not born lame, but that the deformity began to come on after an illness, acute rheumatism (?) when he was about 9 years old. Latterly the deformity had increased so much, that for the last five or six years he had been unable to follow his work at the pit's mouth. Walking about caused severe pain, and life was a burden to him, as he could only sit all his time in a chair, and was dependent on his relations. The deformity was extreme, as in the first case, the feet being drawn back and the toes inwards, so that he could only put the outer side of the little toes to the ground.

On April 15th, 1887, I operated on the left foot in the same manner as on the left foot of the first patient, dividing the tendons first, and making an incision only on the outer side of the foot. The after-treatment was long and tedious, the man being much out of health, with some chronic bronchial trouble, and the wound became septic. In August he was sent to the Scarborough Sea Bathing Infirmary with the foot put up in plasterof-Paris.

$\mathrm{He}$ was re-admitted to the Doncaster Infirmary in November, 1887 , for operation on the right foot. At this operation, as in the second of the former 'case, I made an incision on the inner as well as the outer side of the foot, and divided the tendons first. The case did very well; only on the day after the operation did the temperature rise to $100^{\circ}$. The wound was kept aseptic, but 